\title{
HERNIAS POSTERIORES DOS DISCOS INTERVERTEBRAIS ERRÔNEAMENTE RESPONSABILIZADAS POR NEURALGIAS
}

\author{
Carros Gama*
}

Depois que as hérnias dos núcleos pulposos protrundentes no canal raqueano passaram a ser incriminadas como responsáveis pelas dôres lombares e ciatalgias, houve exagerada aplicação da intervenção cirúrgica para a retirada dêsses tumores intra-raqueanos e, como conseqüência de insucessos terapêuticos em muitos casos, uma certa descrença de que realmente as hérnias posteriores dos discos intervertebrais pudessem ter a importância patogênica que se lhes atribuiu.

Realmente, em análise retrospectiva de achados anatômicos, Virchow já em 1857 e Ribbert em 1911, verificaram a grande freqüência de protrusões do disco intervertebral, e os estudos de Schmörl e Andrae fizeram crer que algumas neuralgias do quadril e dos membros inferiores fôssem devidas àquelas formações. 0 número de publicações sôbre protrusões de discos cresceu em todos os centros médicos mundiais e o $10^{\circ}$ Congresso Sul-Americano de Neurocirurgia, reunido em março de 1945 em Montevidéu, dedicou uma de suas sessões plenárias ao assunto, para integral revisão da literatura e dos conceitos.

Como pessoalmente considero haver exagêro na incriminação das protrusões dos discos intervertebrais como causa das dôres lombares e ciáticas, apresentei à 1.a Jornada Brasileira de Radiologia, em 14 de setembro de 1948 em São Paulo, e à Academia Peruana de Cirurgia, em 27 de outubro de 1948 em Lima, um trabalho sôbre "Hérnias posteriores dos núcleos pulposos dos discos intervertebrais", onde fixava que o diagnóstico seguro de hérnia só é possível por meio da perimielografia, ou melhor, com cineperimielografia, e que a demonstração de que foi o núcleo pulposo o elemento herniado, só é convincente com o exame histológico do material retirado na operação.

Posteriormente, novas observações vieram confirmar minha opinião, e neste trabalho apresento casos convincentes de hérnias comprovadas protrun. dentes no canal raqueano, com documentação radiográfica, um dos quais tratado cirùrgicamente, com diagnóstico histológico de "núcleo pulposo" no material retirado, e que não eram as responsáveis pelas dôres, que só cederam a outros tratamentos.

Caso 1 - J. O. F. (ficha n. 7.652), 61 anos, branco, brasileiro, masculino, casado, fazendeiro, examinado em 30-8-948. Antecedentes pessoais - Em 1918, dôres agudas nas cadeiras, com ruído na espinha ao executar movimento, baixando ou fa-

* Chefe do Serviço de Neurologia e Neurocirurgia da Santa Casa de São Paulo, Brasil (F.I.C.S.). 
zendo esfôrço muscular. Em 1926, sufusões sangiíneas subcutìneas, no dorso, depois de contraturas musculares violentas. História da moléstia atual -- Há um ano, ferroadas no pé esquerdo e, às vêzes, dificuldade na micçĩo. Fêz crenoterapia e radioterapia profunda nas pernas e pés. Há 25 dias, tritamentos locais, ar quente, e radioterapia na coluna vertebral. Exame - Cifose torácica. Atitude antálgica evitando pèso na perna esquerda. Pregaa glútea esquerda mais baixa. Diminuiẹ̃ão do tono dos músculos glúteos, do quadríceps e da panturrilha esquerda. Reflexo a(juiliano abolido à esquerda e diminuído à direita. Dôres em pontadas do joetho esquerdo para baixo, principalmente na planta do pé. Hiperestesia táctil, térmica e dolorosa em $I_{\tilde{j}}$ e $s_{1}$, à esquerda. Pontos de Valleix no ciático esquerdo intensamente dolorosos. Ausência de sinais de Lasìgue e Kernig. Perimielografin (com lipiodol) em 30-8-1948, sob radioscopia em posiçòes ântero-posterior e perfil, cm decúbito ventral, mostrando imagem de hérnia entre $\mathrm{I}_{3}$ e $\mathrm{I}_{+}$(fig. 1).
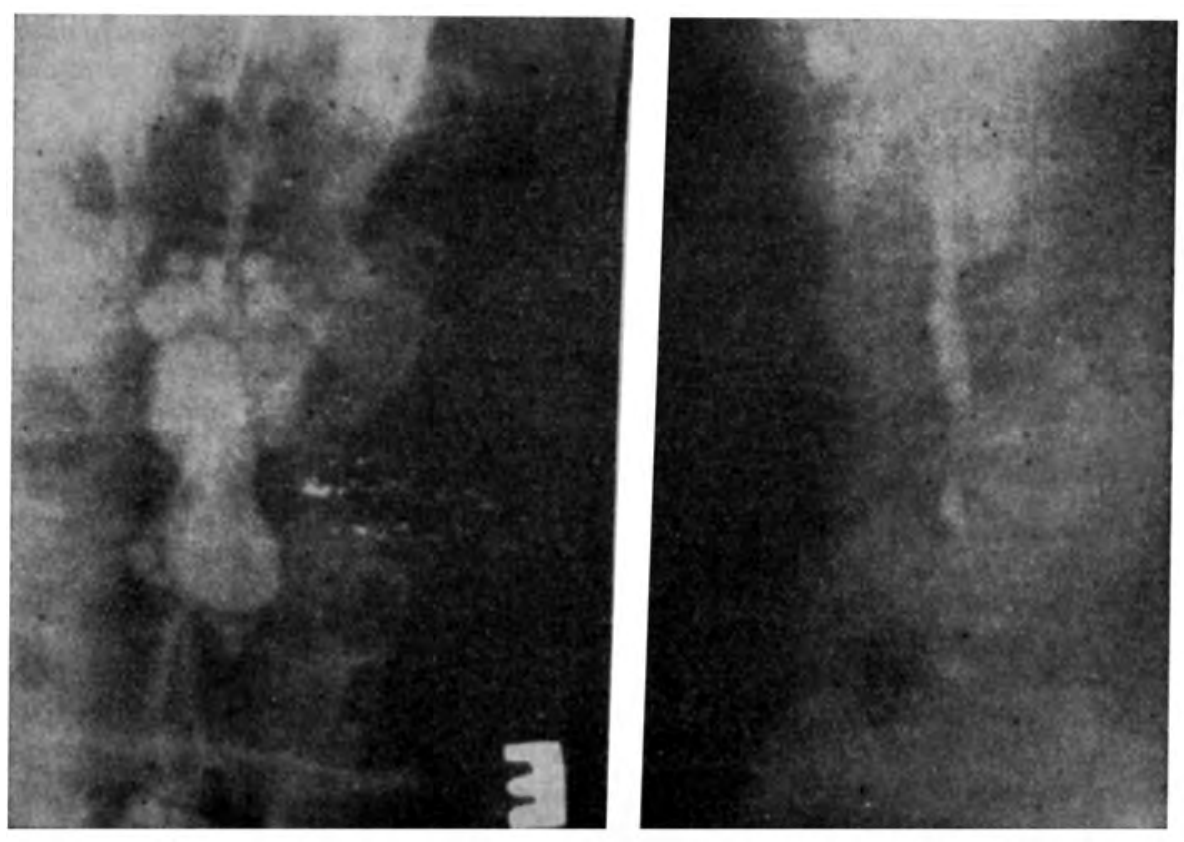

Fig. 1 - Caso J. O. F. Perimielografia com Lipiodol mostrando imagem de hérnia entre $I_{4}$ e $I_{4}$.

1.4 Operação (Hérnia do disco) - Em 2-9-1948, secção da apófíse espinhosa de $I_{4}$ e parcialmente de $L_{3}$ e $L_{5}$. Retirada das metades esquerdas dos arcos de $I_{: ;}$e $I_{4}$. Verificação do obstáculo intra-raqueano, que elevava a raiz nervosa; retiratio com curetas, poupando-se a raiz, rompeu-se a dura, escoando líquiido com gordura (lipiodol:). Pós-operatório bom. Alta cirúrgica em 10-9-1948. Evolução - Queixa persistente de dôres e de dormência no pé esquerdo. No entanto, o exame revelava redução da área de anestesia. O paciente passou a andar melhor. Radioterapia profunda na coluna vertebral e mássagens nas pernas. Fm 21-9-1948 foram encontracios nódulos duros, extremamente dolorosos, cuja palpação produzia dôr irradiante até o pé. Em 23-9-1948 foi feita biópsia do nódulo tumoral dependente do nervo ciático esquerdo no $1 / 5$ inferior da coxal, sob anestesia local, tendo o exame histológico mos- 
trado tratar-se de "neurinoma (Verocay), fibroblastoma perineural (Penfield)" (a. Dr. W. E. Maffey).

2.a operação (Neurinomạ do nervo ciático esquerdo no $1 / 3$ inferior da coxa) Em 28-9-1948, sob anestesia venosa com Thionembutal (Pentotal sódico) foi retirado o tumor do nervo (fig. 2) e feita neurorrafia término-terminal. Imobilização em goteira com flexão do joelho. Piss-operatório bom, tendo o paciente se retirado, em 15-10-1948, para o Interior, aos cuidados do médico da família. Revimos o paciente em 4-5-1949. O paciente obstinadamente queria submeter-se à alcoolização do nervo ciático, contrariando minhas instruçōes, sendo-lhe proposta a cordotomia anterolateral cruzada para alívio das dôres. Em setembro de 1949 um cirurgião do Interior fêz exposição do ciático no ponto onde existia o neurinoma e fêz a neurorrafia, encontrando o nervo com ótimo aspecto; mesino assim infiltrou o perinervo com álcool diluído. Em 1t-11-1949 o paciente foi novamente internado em nosso serviço. Apresentava retração do membro inferior esquerdo, com acentuadas amiotrofias, retrações tendinosas. pseudo-anciloses na coxofemural e no joetho, alterações tróficas nos fâneros do pé esquerdo; dôres insuportáveis nos quadris e perna esquerda, estando o paciente viciado no uso de injeções de morfina.

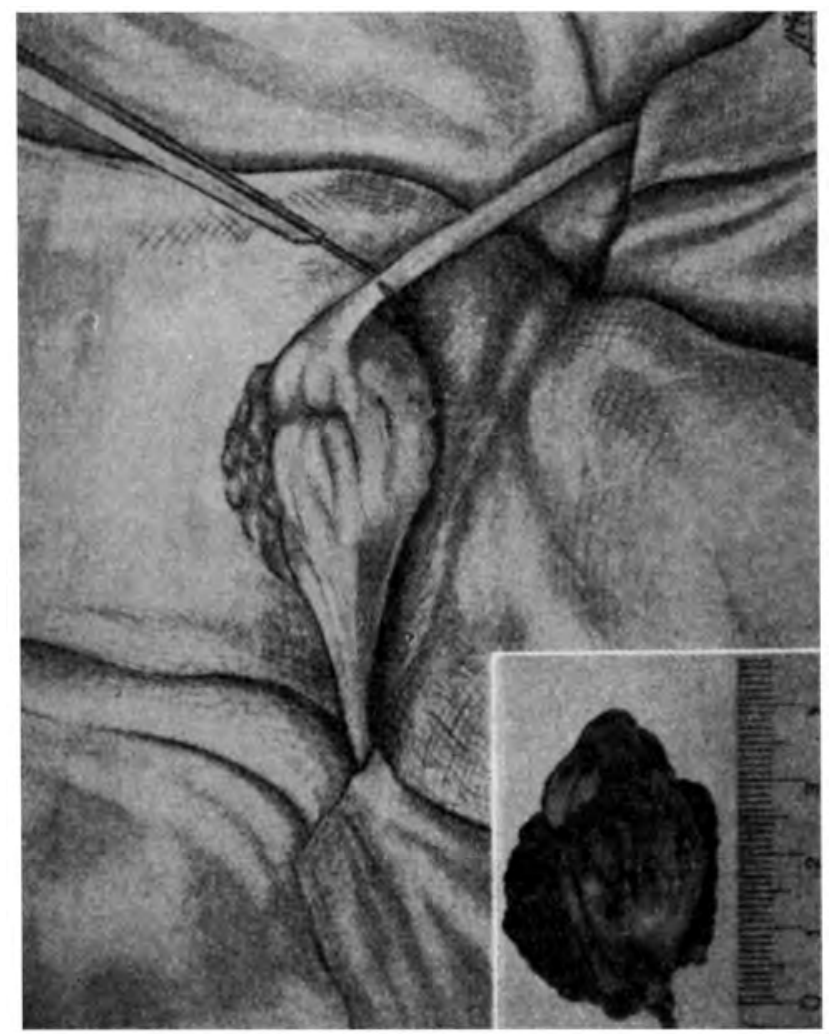

Fig. 2 - Caso J. P. F. Desenho do achado operatório e fotografia do tumor excisado.

$3 .^{a}$ operação (Cordotomia) - Em 15-11-1949, foi praticada cordotomia anterolateral cruzada, na attura de $\mathrm{T}_{6}$. Hzolução pos-operatória muito boa. Eliminação dos tóxicos. Desde logo, massagens nos músculos e mobilização das articulações en- 
durecidas. Resultado excelente: em 15-1-1950 o paciente estava sem dîres, com ampla movimentação em tôdas as articulações e já recomieçando a marcha com apôio de bengala.

Caso 2 - P. I. (ficha n. 8.059), 62 anos, branco, brasileiro, viúvo, industrial, examinado em 18-12-1949. Antecedentes pessoais - Em 1935, baixando-se, sentiu dor aguda na coluna vertebral, ficando com dificuldade para andar. Daí por diante sofreu várias crises de dôres, durante as quais ficava com a espinha entortada e a marcha comprometida. História da moléstia atual - Há 45 dias tem dôres nas costas, que há 15 dias se irradiaram para o membro inferior esquerdo partindo da nádega, passando atrás do joelho $\mathrm{e}$ indo até o tornozelo. A tosse e o espirro não influem sôbre as dôres da perna, porém agravam as da coluna vertebral. Exame - Paciente emagrecido e em semitorpor pela ação de injeções de morfina. Reflexos profundos vivos no membro inferior esquerdo. Sinal de Babinsky presente bilateralmente. Pequenas clôres à pressão do nervo ciático esquerdo na goteira isquiotrocantérica e no cavo poplíteo esquerdos. Não existem dôres nem à pressão nem à percussão das apófises espinhosas lombares e sacras. Exame do líqüido cefalorraquẹno - Punção lombar, deitado; pressão inicial 11, pressão final 7 ; prova de Stookey mostrando boa permeabilidade do canal raquidiano; líquor límpido e incolor; cloretos 7,0 g por litro; proteinas $0,40 \mathrm{~g}$ por litro; glicose $0,61 \mathrm{~g}$ por litro; citologia 0,6 células por $\mathrm{mm}^{3}$; reações de Pandy e Nonne, leve opalescência; r. benjoin 00000.12210.00000.0; reações de Takata-Ara, Wassermann, Eağle e Steinfeld, negativas; reação para cisticercose negativa (Dr. A. J. Brandi). Perimielografia (Pantopaque $3 \mathrm{~cm}^{3} \mathrm{em}$ injeção lombar, deitado) - Em 23-12-1949 o contraste foi observado em radioscopia no seu trânsito intra-raqueano nas posições de Trendelemburg, em decúbito ventral, parando entre $L_{3}$ e $L_{4}$ (fig. 3). Espondilite crônica com numerosos osteófitos e deformaçỏes dos corpos vertebrais lombares. Novas radiografias, 24 horas depois, mostraram intenso processo de funiculite das raizes lombares esquerdas, mais intenso na $2 .^{*}$ e $3 .^{*}$ lombares.

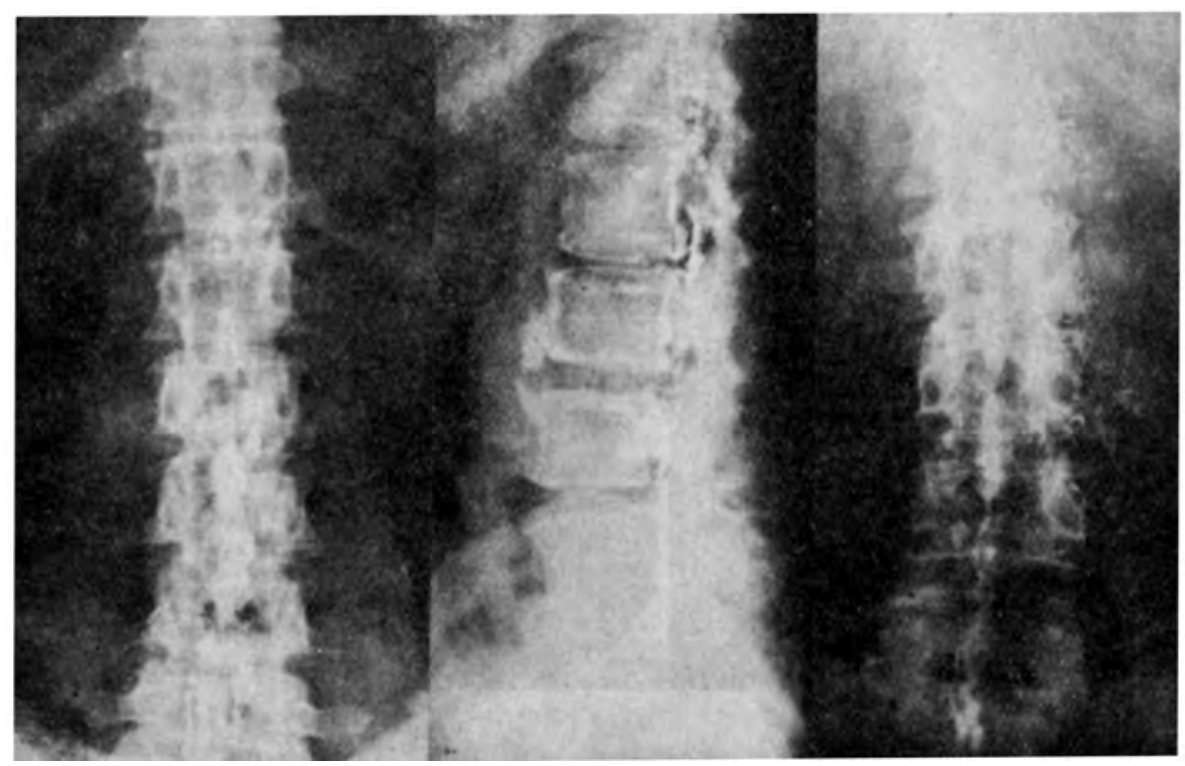

Fig. 3 - Caso P. I. Perimielografia com Pantopaque mostrando deformação da coluna de contraste entre $L_{3}$ e $L_{4}$ e intenso processo de espondilite crônica. 
Tratamento - Aplicações de radioterapia profunda sôbre a coluna lombar. Desde a 2." aplicação desapareceram completamente as dôres, voltando o paciente às suas atividades.

\section{COMENTARIOS}

No caso 1 foi demonstrada a existência de hérnia posterior do disco entre $L_{3}$ e $L_{4}$ por meio de perimielografia e, operado o paciente, o material protrundente no canal revelou-se, ao exame histológico, ser núcleo pulposo, caracterizado pelas células "physallidas" de permeio a material colágeno. O paciente não melhorou com a operação e ulteriores exames mostraram a existência de um tumor no nervo ciático esquerdo. Operado dêste tumor e feita a neurorrafia, o exame do material mostrou tratar-se de neurinoma. Durante a reconstituição do nervo foi feita, errôneamente, uma infiltração perineural com álcool, determinando neurite, com imobilização do membro inferior em flexão, trazendo retrações tendinosas e anciloses. Agravadas as dôres, e viciado o paciente no uso de morfina, foi presiso praticar uma cordotomia anterolateral cruzada alta, depois do que, com massagens e ginástica, o membro esquerdo foi alongads, tendo o paciente recuperado a marcha. Portanto, existia uma hérnia intra-raquidiana do núcleo pulposo, porém, ela não era responsável pelas neuralgias do paciente.

No caso 2 havia história clínica sugestiva de protrusão intra-raqueana do disco, acompanhada de processo espondilartrítico nítido da região lombar. 0 exame do líquor cefalorraqueano mostrou aumento substancial da taxa de proteínas. A perimielografia provou a existência de hérnias posteriores do disco $L_{3}$ e $L_{4}$; outras radiografias de contrôle feitas no dia seguinte demonstraram que o contraste havia penetrado, quase todo, nas bainhas das raízes do ciático esquerdo, caracterizando uma radiculite. Com o tratamento medicamentoso e radioterapia, em 24 horas desapareceram completamente as dôres. Logo, havia hérnia protrundente no canal, mas as dôres eram devidas a outra causa.

\section{CONCLUSOES}

1) A evidência de hérnia posterior do núcleo pulposo do disco intervertebral, não é prova absoluta de ser ela a causa de dôres lombares e ciáticas.

2) Podem coexistir protrusão de disco e outro processo, sendo êste o responsável pelas dôres.

3) Nestes casos, a retirada da hérnia do disco não traz alívio das dôres.

4) Sempre que fôr possível o diagnóstico concomitante de hérnia do disco e outro processo passível de tratamento medicamentoso e fisioterápico, êste deverá ser feito antes de decidir a operação da hérnia.

5) A falta de compreensão exata dêstes fatos pode ser causa de descrédito da eficiência do tratamento cirúrgico das protrusões do disco. 


\section{SUMMARY}

Neuralgic pain wrongly ascribed to posterior hernia of intervertebral disc:.

In the first case the presence of posterior hernia of the intervertebral disc was proved by roentgenologic and histologic examination of the material excised at operation, demonstrating the presence of physalides in the midst of the collagenous tissue. The patient failed to improve after the operation because a neurinoma existed in the left sciatic nerve. Wrongly, alcoholization of the nerve was done, and this resulted in neuritis with its corsequences. Because of the excruciating pain and because the patient had become addicted to morphine, a crossed anterolateral cordotomy was subsequently performed and enabled the patient to recover with the help of massage and calisthenics.

Case 2 suggests the posterior hernia accompanied by a spondyloarthritic process of the lumbar column. Examination of the cerebrospinal fluid demonstrated a high protein level. Roentgen examination showed protruding hernia of the disc of the third and fourth lumbar vertebrae, and some plates showed the contrast medium penetrating the root-sheaths of the left sciatic nerves, demonstrating radiculitis. Roentgen therapy was administered, and in twenty-four hours the pain disappeared. 